\title{
Green synthesis via electrolysis in microemulsions*
}

\author{
James F. Rusling \\ Department of Chemistry, Box U-60, University of Connecticut, Storrs, CT 06269- \\ 3060, USA
}

\begin{abstract}
Electrolysis in microemulsions is a promising approach for environmentally friendly chemical synthetic methods of the future. Employing microemulsions instead of organic solvents for electrosynthesis has the advantages of lower toxicity and cost, high dissolving power for reactants and mediators of unlike solubility, enhancement of reaction rates by controlling the reduction potentials of mediators, possible reaction pathway control, and recycling of microemulsion components. This paper reviews recent progress in using microemulsions for direct and mediated electrosynthesis, including formation of carbon-carbon bonds. Rates of mediated reactions can be controlled by manipulating microemulsion composition. Examples are presented, in which reaction pathways of direct and mediated electrolyses can be controlled with microemulsions to give desired products in high yields. Such control has been demonstrated with dissolved and surface-bound mediators. For a covalently linked scaffold of poly(L-lysine) and cobalt corrin vitamin $\mathrm{B}_{12}$ hexacarboxylate attached to graphite, catalytic turnover rate for reduction of 1,2-dibromocylcohexane was optimized by optimizing microemulsion composition.
\end{abstract}

\section{INTRODUCTION}

It has long been realized that electrolytic methods are well suited to clean syntheses of organic chemicals. Reducing or oxidizing power in electrolysis is controlled by voltages applied to electrochemical cells. Chemical oxidants or reductants are not needed, and waste disposal problems from their reaction products are minimized. A wide variety of electroorganic syntheses are possible [1-3].

Compared to organic solvents, water is a desirable medium for industrial electrolyses for both economic and environmental reasons. However, water cannot always dissolve the organic reactants in sufficient amounts. One option is to employ an emulsion of the organic reactant and water, as in the Monsanto process that produces over one billion pounds per year of adiponitrile, the precursor to hexamethylenediamine in manufacturing Nylon 66 [2].

In the 1950s, Schulman added long-chain alcohols to surfactant-stabilized oil-in-water $(\mathrm{o} / \mathrm{w})$ emulsions to obtain very stable homogeneous fluids [4] that he called microemulsions. These systems had droplet sizes of 10-50 nm, much smaller than conventional emulsions. Microemulsions have since attracted wide interest as possible low-toxicity, low-cost media for tertiary oil recovery [5], formation of nanoparticles [6], purification of proteins [7], drug delivery [8], and decomposition of toxic pollutants [9] and chemical warfare agents [10]. These fluids can be tuned for specific applications by adjusting their compositions $[11,12]$.

\footnotetext{
*An issue of reviews and research papers based on presentations made at the IUPAC/ICSU Workshop on Electrochemistry and Interfacial Chemistry in Environmental Clean-up and Green Chemical Processes, Coimbra, Portugal, 6-7 April, 2001.
} 
Employing a microemulsion instead of an organic solvent in electrosynthesis has the advantages of lower toxicity and cost [13], high dissolving power for reactants and mediators of unlike solubility, enhancement of reaction rates by controlling $\mathrm{E}^{\circ}$ of mediators [14], possible reaction pathway control [14], and recycling of microemulsion components. Thus, electrochemical synthesis in microemulsions promises to contribute significantly to "green" electrochemical synthetic methods of the future. This paper is a review of recent progress in electrosynthesis in microemulsions in our laboratory.

\section{MICROEMULSION STRUCTURE}

The unique stability, solubilization, and optical clarity of microemulsions depends on their nanometerscale structures. Surfactant molecules in these fluids reside at oil-water interfaces and lower the interfacial free energy to very nearly zero, resulting in the formation of optically clear, thermodynamically stable microemulsions $[11,13,14]$. Charged or polar head groups of the surfactants reside on the water side of the interface, and hydrocarbon tails extend into the oil phase. Conductive microemulsions are readily adaptable to electrolytic applications in conventional electrochemical cells. Conductivity is imparted by ionic surfactant or salt and a continuous water phase. One type of microemulsion contains droplets of oil in a continuous water phase and is called an oil-in-water or o/w microemulsion (Fig. 1). Droplets have diameters in the range $10-100 \mathrm{~nm}$. Surface charge on the droplets leads to interfacial potentials on the order of $100 \mathrm{mV}$. Another type of conductive microemulsion features continuous oil and water phases intertwined in dynamic extended networks (Fig. 1) and is called a bicontinuous microemulsion. Some surfactants used to prepare microemulsions are shown in Fig. 2. Preparation of known microemulsions is straightforward, and usually involves mixing of surfactant, cosurfactant, oil, and water in the proper proportions [11].

Surfactants in microemulsions adsorb onto electrode surfaces. These adsorbed layers sometimes exert a strong influence on electrochemical reactions [14]. However, in many cases, electrochemical reactions behave similarly to homogeneous solvents in terms of electrochemical theory, although kinetics, pathways, and even products may be very different.

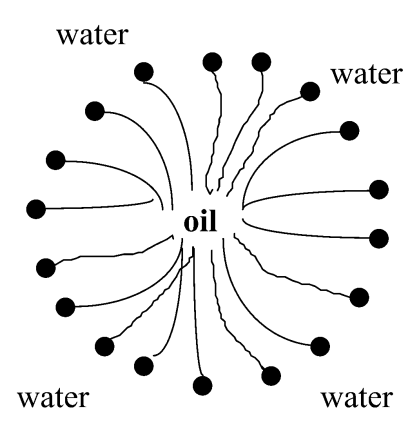

o/w microemulsion

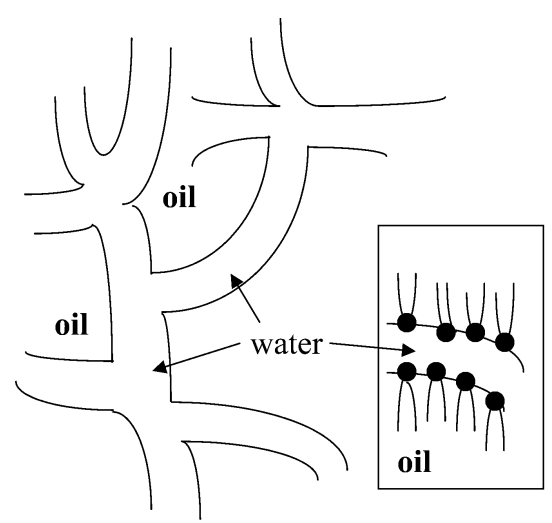

bicontinuous microemulsion

Fig. 1 Oversimplified representations of structures of microemulsions useful for electrosynthesis. 

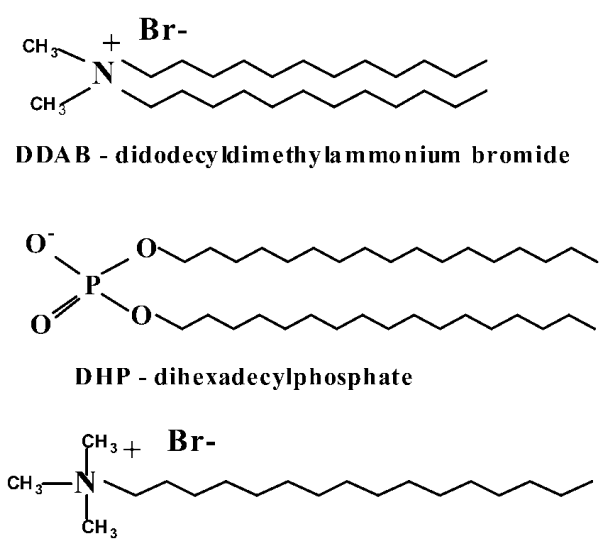

C TAB - cety lt rimethylam monium bromide

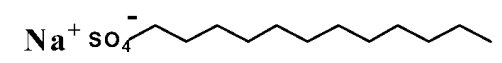

SDS - sodium dodecylsulfate

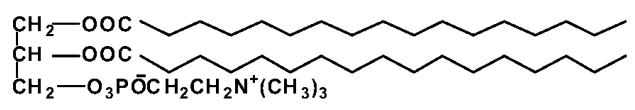

PC - phosphatidylcholine (lecithin)

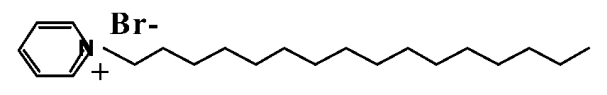

cetylpyridinium bromide

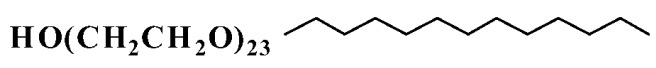

Brij-35 polyoxyethylene( 23 )dodecyl ether

Fig. 2 Some surfactants useful for making microemulsions.

\section{DIRECT ELECTROCHEMICAL REACTIONS}

Reactions in which pathway control can be achieved by microemulsions may provide synthetic routes to products that are difficult to make in other ways. A few examples of pathway control in direct electrochemical reductions are given below.

Electrolysis of nitrobenzene at $-1.5 \mathrm{~V}$ vs. $\mathrm{Ag} / \mathrm{AgNO}_{3}$ in $\mathrm{DDAB} /$ hexane/water microemulsions gave dimers 1 and 2 [15], even when the microemulsion was strongly acidified. No hydroxylamine or aniline was detected, suggesting that the reaction takes place at sites of low proton availability where dimerization following initial electron transfer is preferred to protonation and further reduction. In contrast, in homogeneous neutral and weakly acid aqueous solutions, phenylhydroxylamine is always the product. At $\mathrm{pH}<4$, phenylhydroxylamine is reduced to aniline. Dimeric products are formed in homogenous solutions only when they are alkaline [16]. 


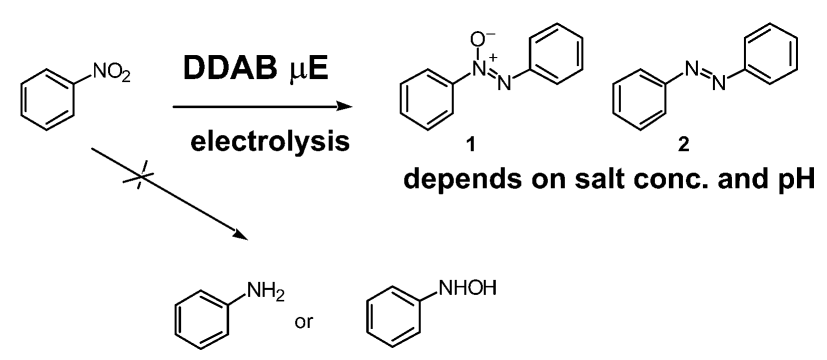

Scheme 1 Nitrobenzene reduction in microemulsions.

Constant current electrolyses of napthalene and biphenyl in DDAB/hexane/water microemulsions resulted in selective reduction of a single benzene ring in the polyaromatic hydrocarbon [15], as in $3,4,5,7$, and 8 . Products 8 and 9 , in addition to biphenyl, were also found from catalytic reduction of polychorinated biphenyls in microemulsions [17]. Direct electrochemical reduction of aromatic rings is difficult in other media.

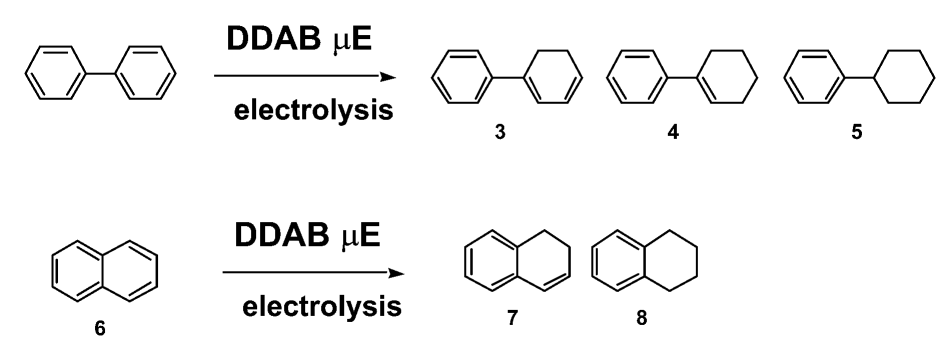

\section{MEDIATED ELECTROCHEMICAL REACTIONS IN MICROEMULSIONS WITH DISSOLVED CATALYSTS}

Mediated or catalytic electrochemical synthesis relies on a mediator or catalyst to shuttle electrons between electrodes and reactants. The two examples shown in Scheme 2 employ macrocyclic complexes such as cobalt salen or cobalt corrins as reduction catalysts. The first step is the direct electrochemical reduction of the $\mathrm{Co}^{\mathrm{II}} \mathrm{L}$ complex to $\mathrm{Co}^{\mathrm{I}} \mathrm{L}$, which then reacts with the organic reactant. In the case of trans-1,2-dibromocyclohexane ( $\mathrm{DBCH})$, a concerted reaction with $\mathrm{Co}^{\mathrm{I}} \mathrm{L}$ gives the olefin directly. In the second example in Scheme 2, an alkyl bromide reacts with $\mathrm{Co}^{\mathrm{I}} \mathrm{L}$ to give an alkylcobalt complex that can be cleaved with visible light or by applying a more negative electrode potential. In this example, the alkyl radical or anion resulting from cleavage can add to the double bond of the cyclohexeneone. The latter reaction is an example of electrochemically catalyzed carbon-carbon bond formation, which is of great importance for syntheses of larger organic molecules. Both of these reactions proceed with high yields in microemulsions, with the carbon-carbon bond formation giving the best yields when $\mathrm{Co}^{\mathrm{I}} \mathrm{L}$ is formed electrochemically and visible light is used to cleave the alkylcobalt bond [18].

Rates of catalytic reduction of DBCH by macrocyclic cobalt complexes $[14,19]$ were measured by voltammetry in order to investigate factors controlling the kinetics of mediated electrochemical reactions in microemulsions. Cobalt corrins, salen, porphyrins, and phthallocyanines were used to achieve a range of $\mathrm{Co}^{\mathrm{II}} \mathrm{L} / \mathrm{Co}^{\mathrm{I}} \mathrm{L}$ formal potentials. In bicontinuous DDAB microemulsions, most of the $\mathrm{Co}^{\mathrm{II}} \mathrm{L}$ mediators resided in the water phase with $\mathrm{DBCH}$ in the oil phase. In such cases, the reaction between $\mathrm{DBCH}$ and $\mathrm{Co}^{\mathrm{I}} \mathrm{L}$ probably occurs at $\mathrm{o} / \mathrm{w}$ interfaces. 


\section{Examples of Electrochemical Catalysis}

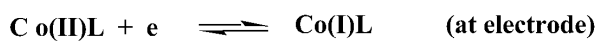

\section{catalytic olefin formation:}

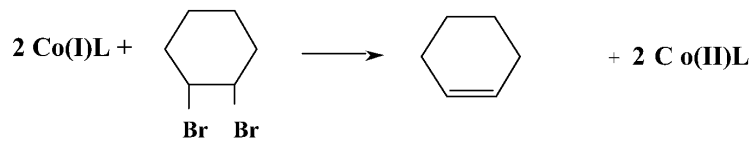

\section{carbon-carbon bond formation:}

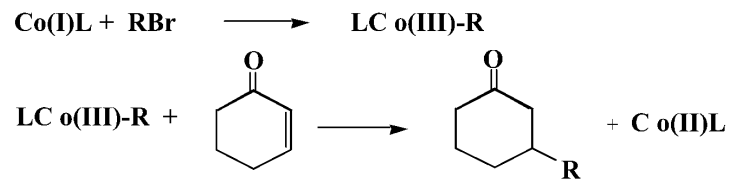

\section{Scheme 2}

Catalytic voltammetric currents were used to measure apparent rate constants $\mathrm{k}_{1}$ for reaction of CoI $L$ with DBCH [19]. A linear plot of $\log \mathrm{k}_{1}$ vs. formal potential ( $\mathrm{E}^{\circ \prime}$ ) of the mediator (Fig. 3) was found, with the same line describing reactions in DDAB microemulsions and in organic solvents. A similar linear plot was found for the catalytic reductions of benzyl bromide and alkyl iodides in microemulsions and organic solvents $[19,20]$. These linear plots indicate that the bimolecular reactions in the microemulsions are controlled by the intrinsic activation free energy of the reaction as controlled by $\mathrm{E}^{\circ \prime}$ of the catalyst, rather than by partition of reactants between oil and water phases. Activation free energy control requires a sufficiently large o/w interfacial area of the microemulsion, otherwise partition of reactants between oil and water phases may lower the observed reaction rates [14]. Also, coadsorption of reactants and catalysts into an adsorbed surfactant layer on an electrode in microemul-

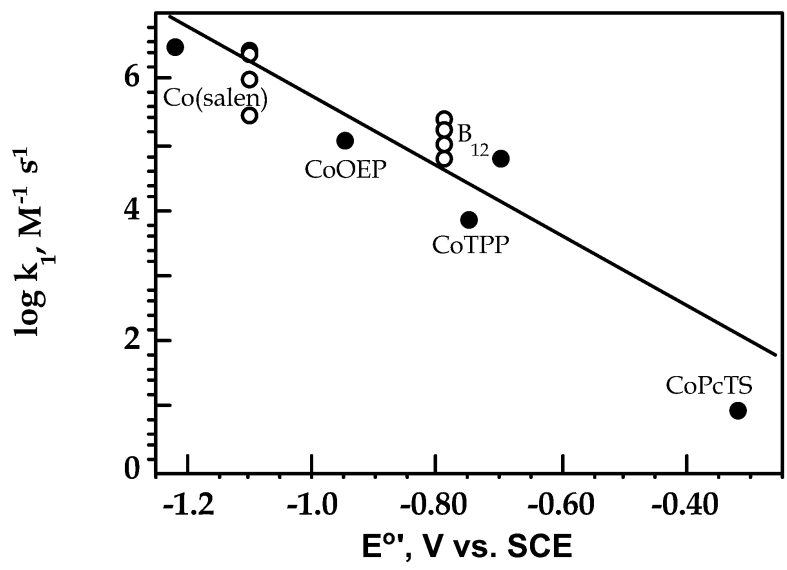

Fig. 3 Influence of catalyst formal potential $\left(\mathrm{E}^{\circ \prime}\right)$ on $\log \mathrm{k}_{1}$ for reaction of $\mathrm{Co}^{\mathrm{I}} \mathrm{L}$ complexes with $\mathrm{DBCH}$ in bicontinuous microemulsions $(\mathbf{O})$ of DDAB/water/dodecane $(21 / 39 / 40)$ and in DMF $(\bullet)$ for dissolved catalysts vitamin $\mathrm{B}_{12}, \mathrm{Co}$ (salen), cobalt phthalocyaninetetrasulfonate (CoPCTS), cobalt tetraphenylporphyrin (CoTPP), and cobalt octaethylporphyrin (CoOEP). Adapted from ref. 19 with permission, (C) American Chemical Society, 1995. 
sions can lead to high concentrations in a restricted reaction volume that can enhance rates of bimolecular reactions.

The carbon-carbon bond-forming catalysis shown above features two chemical steps following the electrochemical formation of the active form of the catalyst, Co $\mathrm{L}_{\mathrm{L}}$. While $\mathrm{Co}($ salen) reacts much faster with benzyl bromide than the cobalt corrin vitamin $\mathrm{B}_{12}$, the rate of formation of dimeric products was still larger for vitamin $B_{12}$ [20]. This reflects the weakness of the alkylcobalt bond of vitamin $B_{12}$, and suggests that breaking this bond is the rate-determining step for carbon-carbon bond formation.

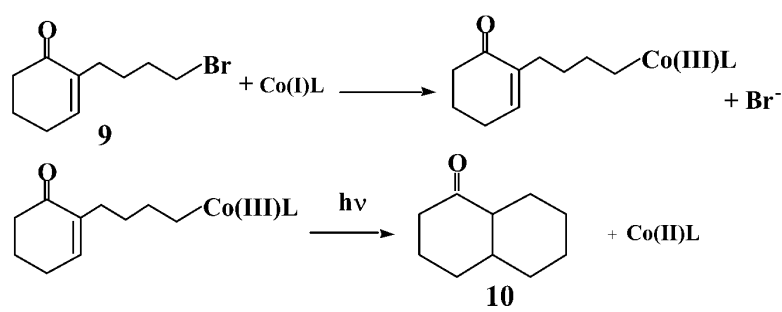

Scheme 3 Formation of trans-1-decalone in high yields in microemulsions.

Cyclization of organic reactants is of great importance in the synthesis of drugs and fine chemicals. Cyclization can be accomplished by electrochemical catalysis mediated by cobalt complexes when the reactant contains alkylhalide and activated olefin moieties on the same molecule. Thus, 4-(bromobutyl)-2-cyclohexen-1-one $\mathbf{9}$ was cyclized to trans-1-decalone $\mathbf{1 0}$ in microemulsions in an electrochemical reaction mediated by vitamin $\mathrm{B}_{12}$ (Scheme 3) [18,21]. Cis- and trans-1-decalone were obtained in $90 \%$ yields with either light or electrochemical cleavage of the alkyl-cobalt bond in microemulsions and in DMF. However, microemulsions gave a high stereoselective ratio of 93:7 trans: cis, compared to about a 3:1 ratio in DMF. Formation of the thermodynamically favored trans-1decalone in microemulsions involved equilibration of isomers via keto-enol tautomerism catalyzed by hydroxide ions formed by co-electrolysis of water [21].

Cyclization of 2-(3-bromopropyl)-2-cyclohexen-1-one 11 to the 5-endo-trig cyclization product 4-hydrindanone 12 (Scheme 4) is forbidden by Baldwin's rules, which predict that a high degree of strain in the transition state leads to very poor yields of the product. However, 12 was obtained in $62-70 \%$ yields using vitamin $\mathrm{B}_{12}$ catalysis at $-1.5 \mathrm{~V}$ vs. SCE at carbon electrodes in CTAB and SDS bicontinuous microemulsions [22]. Similar electrolyses in $\mathrm{DMF}, \mathrm{MeOH}$, or $\mathrm{MeOH} /$ water gave only $7-19 \%$ of 12, and large amounts of reduction side product 14 . The microemulsions seem to provide reaction sites of low proton availability to inhibit protonation of a key carbanion intermediate whose protonation would otherwise prevent cyclization and lead to $\mathbf{1 4}$.

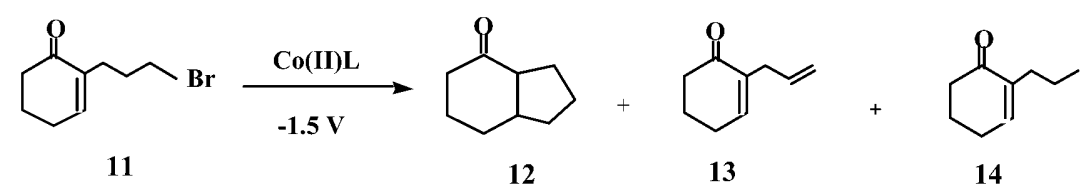

Scheme 4 Cyclization product 12 can be made in good yields in microemulsions.

\section{REACTIONS IN MICROEMULSIONS MEDIATED BY A SURFACE-BOUND CATALYST}

Catalytic films on electrodes designed for synthesis in microemulsions may have a large future technological impact. Reusable electrodes could catalytically produce valuable organic chemicals such as drugs in low-cost, low-toxicity media using only electricity and reactants. Mediated syntheses could be 
designed in flow cells for high turnover. The first milestone needed to reach these goals was to achieve good film stability in microemulsions. Often, catalytic polymer films are adsorbed to electrodes, but because microemulsions are such good solvents, they can easily strip an adsorbed layer of polymer from an electrode.

The most successful strategy to date has been covalent binding of an electroactive polymer onto carbon electrodes. Via amide bonds, we covalently linked poly-L-lysine (PLL) onto oxidized carbon cloth and pyrolytic graphite $(\mathrm{PG})$ electrodes and then attached vitamin $\mathrm{B}_{12}$ hexacarboxylate $(\mathrm{CoL})$ via amide bonds to excess amine groups on the immobilized polymer (Fig. 4) [23]. Covalent linkage was necessary for stability of the catalytic films in microemulsions. Conversion of DBCH to cyclohexene in microemulsions was achieved with much higher turnover rates compared to similar catalysts dissolved in the microemulsion.

The catalytic properties of these PLL-CoL films was controlled by microemulsion composition [24]. In SDS microemulsions, micelles formed within the polymer matrix (Fig. 5) driven by electrostatic interactions of DS- anions with ammonium groups on PLL. SDS and salt concentration could be
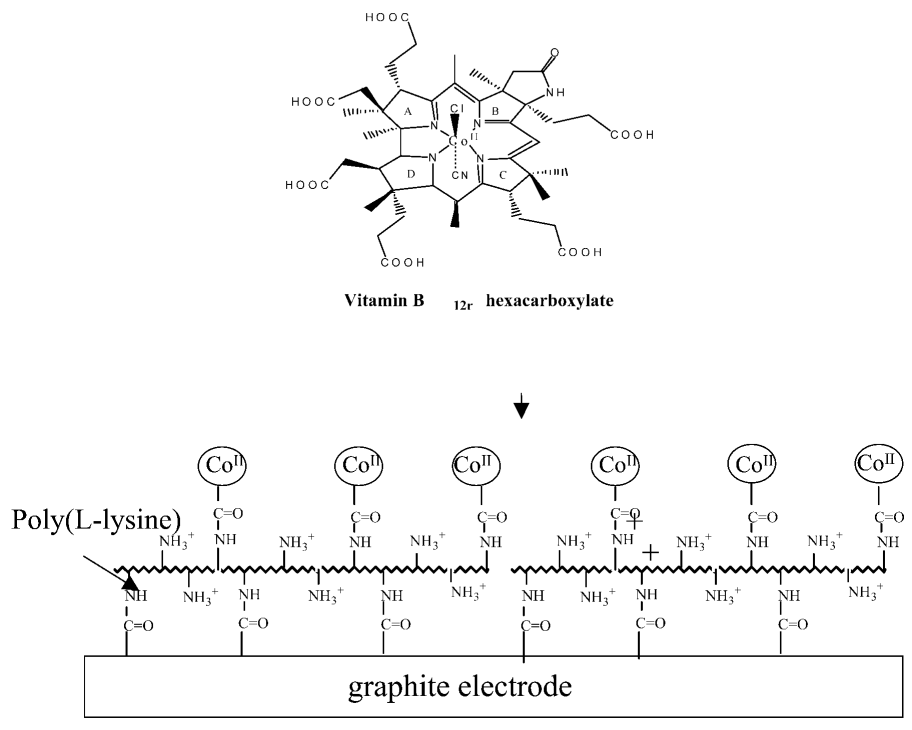

Fig. 4 Conceptual representation of covalently linked films of poly (L-lysine) and vitamin $B_{12 r}$ hexacarboxylate (PLL-CoL) on graphite electrodes.

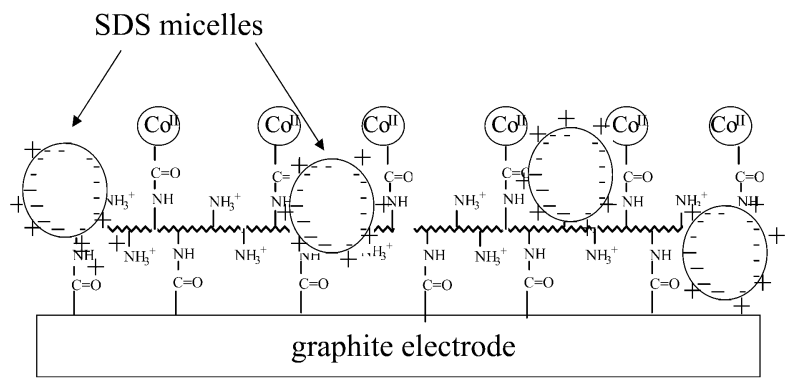

Fig. 5 Conceptual representation of micelle formation within PLL-CoL film when used in SDS microemulsions. 
used to control the catalyst's formal potential (Fig. 6). Note that the direction of formal potential shift with cation concentration was different for CTAB and SDS microemulsions, showing that a wide range of potential control was possible via manipulation of the film's Donnan potential via microemulsion composition [24].

Figure 7 shows cyclic voltammograms representing a catalytic signature for reduction of $\mathrm{DBCH}$ by the PLL-CoL film. The reversible $\mathrm{Co}^{\mathrm{II}} \mathrm{L} / \mathrm{Co}{ }^{\mathrm{I}} \mathrm{L}$ peak pair of the film is converted to a large catalytic reduction peak at about $-0.75 \mathrm{~V}$ vs. SCE upon addition of $\mathrm{DBCH}$. This catalytic peak is roughly one volt positive of the direct reduction peak of $\mathrm{DBCH}$. The ratio of catalytic current by $\mathrm{CV}$ or rotating disk voltammetry (RDV) for DBCH $\left(\mathrm{I}_{\text {cat }}\right)$ to the peak current of the catalytic film $\left(\mathrm{I}_{\mathrm{d}}\right)$ is a voltammetric measure of catalyst turnover rate. Relative turnover for PLL-CoL films was also measured after electrolyses by GC analysis of the amount of olefin product formed per unit time. Both of these measures of turnover rate depended on formal potential (Fig. 8), which is in turn controlled by microemulsion com-

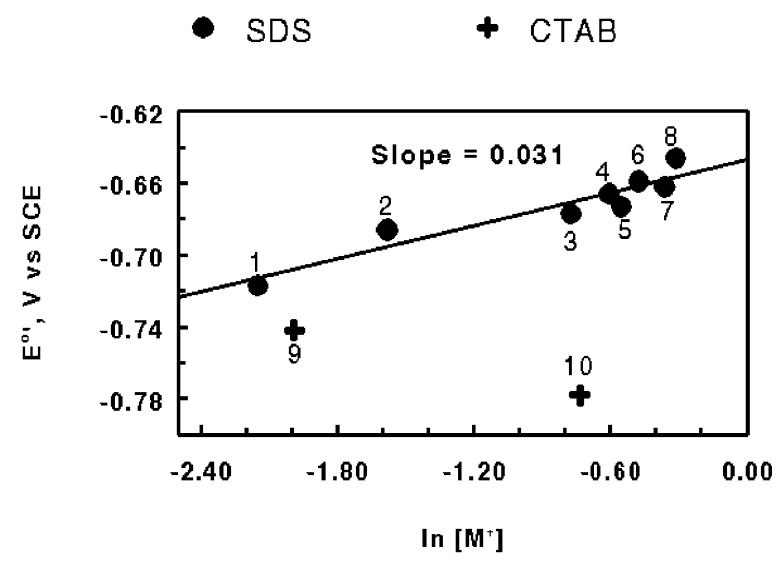

Fig. 6 Influence of total cation concentration in SDS and CTAB microemulsions with and without salt added on the formal potential of PLL-CoL. Numbers near points identify different microemulsions described in ref. 24. Reproduced from ref. 24 with permission, (C) American Chemical Society, 2000.

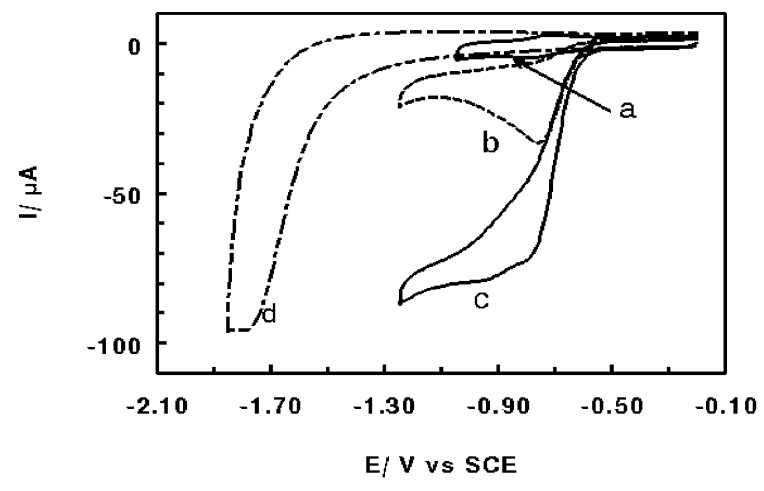

Fig. 7 Representative voltammograms of PLL-CoL film at $50 \mathrm{mV} \mathrm{s}^{-1}$ in SDS microemulsion 1: (a) CV with no $\mathrm{DBCH}$; (b) CV with $7 \mathrm{mM}$ DBCH present; (b) RDV with $7 \mathrm{mM} \mathrm{DBCH}$ present (d) direct reduction of $7 \mathrm{mM}$ DBCH on PG/PLL electrode. Reproduced from ref. 24 with permission, () American Chemical Society, 2000. 
position ( $c f$. Fig. 7). Thus, microemulsion composition controls the rate of this mediated reaction. High conductivity and low viscosity of the bulk microemulsion also facilitated fast catalyst turnover [24].

The influence of attaching additional layers of PLL-CoL was explored to increase the catalyst load per unit electrode area [25]. Quartz crystal microbalance studies showed regular and reproducible layer formation. Turnover was measured by voltammetry and preparative electrolysis in an SDS microemulsion. These films obeyed theoretical predictions of a maximum in voltammetric catalytic efficiency as thickness increased for the reduction DBCH in microemulsions. In films with less than optimum thickness, kinetic control of the chemical reaction between $\mathrm{Co}^{\mathrm{I}} \mathrm{L}$ and $\mathrm{DBCH}$ predominated. As film thickness was increased beyond that found for maximum efficiency, electron and reactant mass transport within the films became limiting factors. However, mass transport of reactant in the microemulsion to the electrode appears to be very important as shown by the much greater catalytic current ratio in hydrodynamically controlled RDV compared to CV in static solution (Fig. 9). For synthet-

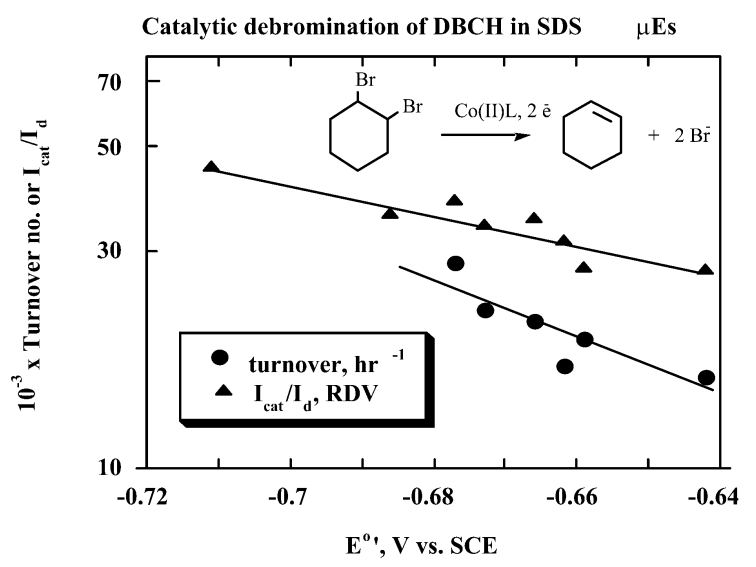

Fig. 8 Influence of formal potential of PLL-CoL films on catalytic turnover rate as $\left(\mathrm{I}_{\text {cat }} / \mathrm{I}_{\mathrm{D}}\right)$ from RDV at $1800 \mathrm{rpm}$ and on the logarithm of turnover rate measured by gas chromatography catalytic electrolyses of DBCH in bicontinuous SDS microemulsions. Adapted from ref. 24 with permission, (C) American Chemical Society, 2000.

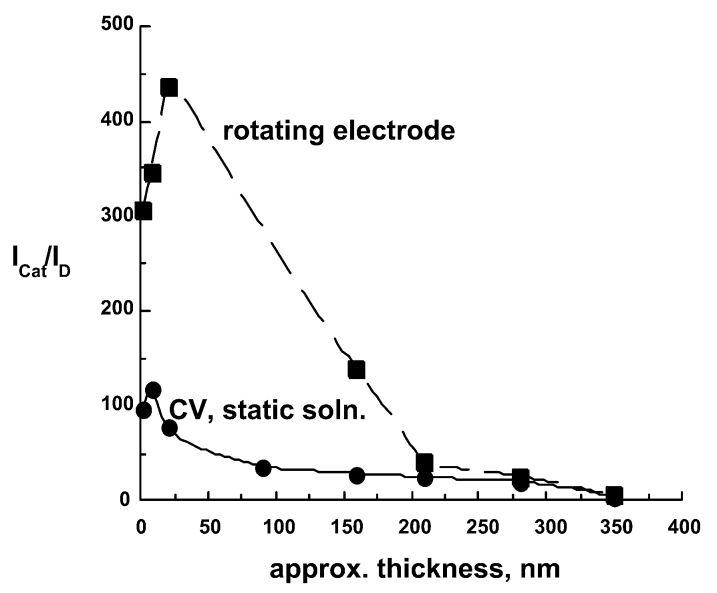

Fig. 9 Influence of thickness of PLL-CoL film on a PG electrode on catalytic turnover rate as $\left(I_{\text {cat }} / I_{D}\right)$ from RDV at $1800 \mathrm{rpm}$ and $10 \mathrm{mV} \mathrm{s}^{-1}$ in an SDS microemulsion containing DBCH. Reproduced from ref. 25 with permission, (C) American Chemical Society, 2001. 
ic electrolyses, optimal turnover was found for very thin films (ca. 20-30 nm) on porous carbon cloth electrodes, and best yields and current efficiencies were obtained with a catalyst coverage of about $2 \mathrm{nmol} \mathrm{cm}{ }^{-2}$. Recent results showed that improving reactant mass transport by using appropriate flow cell designs lead to large increases in turnover numbers. Carbon-carbon bond-forming reactions (e.g., Schemes 2, 3, and 4) have also been successfully catalyzed by PLL-CoL films.

\section{SUMMARY AND CONCLUSIONS}

While electrochemical synthesis in microemulsions is still in an early stage of development, we have seen that direct electrolyses, mediated electrolyses with dissolved catalysts, and mediated electrolyses with covalently bound catalyst films on electrodes all have excellent synthetic utility. In addition to the obvious advantages of excellent solubilization of reactants, low cost, and low toxicity, reaction pathways can be controlled and altered with microemulsions. Rates of mediated reactions can be enhanced by manipulating microemulsion composition. Reaction products and microemulsion components are easily recovered via adsorption on silica or alumina columns or by phase transition methods. All indications at present are that electrolysis in microemulsion is a promising approach for "green" chemical syntheses of the future.

\section{ACKNOWLEDGMENTS}

The authors are grateful to the U.S. National Science Foundation for financial support via Grants Nos. CTS-9632391 and 9982854, and to Prof. James M. Bobbitt and other coauthors of our research papers on this topic, without whose excellent contributions progress in this project would not have been possible.

\section{REFERENCES}

1. M. M. Baizer and H. Lund (Eds.). Organic Electrochemistry, $2^{\text {nd }}$ ed., Marcel Dekker, New York (1983).

2. D. Pletcher and F. C. Walsh. Industrial Electrochemistry, $2^{\text {nd }}$ ed., Blackie Academic, London (1993).

3. A. J. Fry. Synthetic Organic Electrochemistry, $2^{\text {nd }}$ ed., Wiley-Interscience, New York (1989).

4. A. A. Adamson. Physical Chemistry of Surfaces, $5^{\text {th }}$ ed., Wiley, New York, pp. 525-559 (1990).

5. C. A. Miller and S. Qutubuddin. "Enhanced oil recovery with microemulsions" in Interfacial Phenomena in Apolar Media, H. F. Eicke and G. D. Parfitt (Eds.), p. 117, Marcel Dekker, New York (1987).

6. J. H. Fendler and K. Kurihara. "Microemulsion, surfactant vesicle, and polymerized surfactant vesicle entrapped colloidal catalysts and semiconductors", in Metal Containing Polymeric Systems, J. E. Sheats, C. E. Carraher, C. U. Pittman (Eds.), pp. 341-353, Plenum, New York (1985).

7. P. L. Luisi and L. Magid. CRC Crit. Rev. Biochem. 20, 409 (1987).

8. D. Attwood and A. T. Florence. Surfactant Systems, Chapman and Hall, London (1983).

9. J. P. Zelina and J. F. Rusling. "Electrochemical remediation of soils" in Encyclopedia of Environmental Analysis and Remediation, Vol. 3, R. A. Myers (Ed.), pp. 1567-1583, Wiley, New York (1998).

10. R. A. Mackay. "Chemical detoxification in amphiphilic systems", in Reactions and Synthesis in Surfactant Systems, J. Texter (Ed.), pp. 373-384, Marcel Dekker, New York (2001).

11. M. Bourrel and R. S. Schechter. Microemulsions and Related Systems, Marcel Dekker, New York (1988). 
12. (a) R. A. Mackay and J. Texter (Eds.). Electrochemistry in Colloids and Dispersions, VCH, New York (1992); (b) J. F. Rusling. "Electrochemistry and electrochemical catalysis in microemulsions" in Modern Aspects of Electrochemistry, No. 26, B. E. Conway and J. O’M. Bockris (Eds.), pp. 49-104, Plenum, New York (1994).

13. S. Friberg. Adv. Colloid Interface Sci. 32, 167 (1990).

14. J. F. Rusling. "Mediated electro-organic synthesis in microemulsions", in Reactions and Synthesis in Surfactant Systems, J. Texter (Ed.), pp. 323-335, Marcel Dekker, New York (2001).

15. H. Carrero, J. Gao, J. F. Rusling, Che-Wah Lee, A. J. Fry. Electrochemica Acta 45, 503 (1999).

16. A. J. Fry. Synthetic Organic Electrochemistry, $2^{\text {nd }}$ ed., Wiley, New York (1989).

17. S. Zhang and J. F. Rusling. Environ. Sci. Technol. 27, 1375 (1993).

18. J. Gao, J. F. Rusling, D.-L. Zhou. J. Org. Chem. 61, 5972 (1996).

19. D.-L. Zhou, J. Gao, J. F. Rusling. J. Am. Chem. Soc. 117, 1127 (1995).

20. D.-L. Zhou, H. Carrero, J. F. Rusling. Langmuir 12, 3067 (1996).

21. J. Gao, C. K. Njue, J. K. N. Mbindyo, J. F. Rusling. J. Electroanal. Chem. 464, 31 (1999).

22. J. Gao and J. F. Rusling. J. Org. Chem. 63, 218 (1998).

23. D.-L. Zhou, C. K. Njue, J. F. Rusling. J. Am. Chem. Soc. 121, 2909 (1999).

24. C. K. Njue and J. F. Rusling. J. Am. Chem. Soc. 122, 6459 (2000).

25. C. J. Campbell, C. K. Njue, B. Nuthakki, J. F. Rusling. Langmuir 17, 3447 (2001). 